\title{
MARÍA DEL MAR SÁNCHEZ RAMOS. 2020. DOCUMENTACIÓN DIGITAL Y LÉXICO EN LA TRADUCCIÓN E INTERPRETACIÓN EN LOS SERVICIOS PÚBLICOS (TISP): FUNDAMENTOS TEÓRICOS Y PRÁCTICOS. BERLÍN: PETER LANG, 184 PÁGINAS. ISBN: 978-3-631-80849-8.
}

\section{Reseñado por Míriam Pérez-Carrasco \\ Universidad de Málaga, España miriamperez@uma.es}

Esta monografía es el resultado de una investigación centrada en el ámbito de la traducción e interpretación en los servicios públicos (TISP), que pretende dar cuenta del gran avance que este campo ha experimentado en las últimas décadas y de su necesaria consolidación en los estudios de Traducción, tomando en especial consideración dos aspectos que la autora considera fundamentales para los traductores e intérpretes de los servicios públicos: la documentación digital y el bagaje léxico.

La obra queda dividida en una introducción, seguida de cuatro capítulos principales, cada uno con sus respectivas secciones, conclusiones y un extenso apartado de referencias bibliográficas, a los que se suman un índice de figuras y otro de tablas. Esta disposición de las diferentes partes facilita la lectura de la monografía, así como la localización de aquellas partes que puedan interesarnos particularmente. Además, los datos contenidos en cada capítulo se muestran ordenados desde lo más general a lo más particular, facilitando la comprensión de la información dispuesta en cada uno de ellos.

De esta manera, en el primer capítulo, titulado "Traducción y multiculturalidad: Traducción e Interpretación en los Servicios Públicos (TISP)”, Sánchez Ramos contextualiza esta monografía y realiza un repaso de la situación actual y el recorrido realizado hasta ahora en el ámbito de la TISP. El capítulo comienza mostrando algunas de las definiciones que se han ofrecido sobre esta modalidad, así como la controversia terminológica originada al respecto. En la siguiente sección de este capítulo se explican, por una parte, los esfuerzos realizados en España por consolidar la TISP y su progresión a lo largo del tiempo. Por otra parte, puede resultar de gran interés el listado donde muestra grupos de investigación, revistas, asociaciones y algunos de los congresos celebrados en nuestro país cuyo tema central es la TISP y cómo todas estas iniciativas siguen ayudando a superar los retos a los que se ha enfrentado esta modalidad desde sus inicios hasta hoy en día. Por otro lado, en el último apartado de este primer capítulo se trata la formación universitaria en TISP. En primer lugar, se subraya el creciente interés que ha surgido en cuanto a la instrucción pedagógica en este ámbito, apoyado sin duda en las necesidades surgidas en el mundo laboral. En segundo lugar, se citan las diversas propuestas formativas que existen hoy en día en España, incluyendo programas de posgrado, especialistas y cursos de experto.

El segundo capítulo de este volumen se titula "Fundamentos teóricos para la TISP I: Contextualización del léxico en los modelos de competencia traductora". Este se centra en el componente léxico y en conocer el lugar que este ocupa en las distintas propuestas realizadas 
desde la Traductología. Con este fin, se revisan algunos de los modelos más significativos sobre la competencia traductora, desde que Chomsky acuñara el término en 1965 hasta la fecha, para luego examinar dónde se sitúa el componente léxico en dichos modelos. Asimismo, la autora describe otros conceptos más generales, como son competencia y competencia comunicativa. Las preguntas que se plantea Sánchez Ramos al inicio del capítulo son: “¿Conviene rescatar el componente léxico para mejorar la formación del traductor y del intérprete en los servicios públicos?, y ¿de qué forma?", para llegar al final a la conclusión de que el componente léxico está siempre presente en las distintas propuestas de competencia traductora, de una u otra manera, y que además es fundamental en la formación del traductor e intérprete de la TISP, pues ayudaría, en palabras de la autora, "a solventar gran parte de los problemas que los alumnos de traducción presentan en las aulas".

La autora dedica el tercer capítulo, denominado "Fundamentos teóricos para la TISP II: Contextualización del léxico en la didáctica de la traducción", a indagar cuál es el lugar que ocupa el componente léxico en los diversos modelos de la didáctica de la traducción para incorporar los fundamentos teóricos de esta a la TISP y poder así ofrecer un modelo de competencia léxica traductora en la TISP. Como subraya Sánchez Ramos, el componente léxico supone una de las necesidades lingüísticas básicas que debe poseer el traductor e intérprete de la TISP, pues deben adquirir, ampliar y consolidar el vocabulario especializado con el que se van a encontrar durante el desempeño de su actividad profesional. Tras mostrar algunos de los estudios más relevantes sobre la formación de traductores, la autora plantea, para cerrar el capítulo, su propuesta sobre la competencia léxica traductora aplicada a la TISP. La pregunta clave que sugiere Sánchez Ramos es la siguiente: “¿Qué tiene que saber un traductor e intérprete para conocer en profundidad una palabra?". Con el fin de dar respuesta a la misma, presenta una aportación personal de gran utilidad. Consiste en un modelo que incluye los puntos que ella considera elementales y que el propio docente puede usar como hilo conductor a la hora de enseñar al alumnado de traducción e interpretación en el ámbito de los servicios públicos qué es la competencia léxica traductora y qué conlleva conocer un término, tanto desde el punto de vista receptivo como productivo en nuestras diferentes lenguas y combinaciones de trabajo.

El cuarto y último capítulo se titula "Fundamentos prácticos para la TISP: Documentación digital y la TISP". Está dedicado en exclusiva a la documentación digital y pretende poner de manifiesto su gran repercusión en este ámbito de la traducción e interpretación. De esta forma, el capítulo comienza con un repaso de las transformaciones que la era digital supone para la transferencia de información y en cómo afecta al campo de la TISP, en concreto en el proceso de gestión y búsqueda documental para el ejercicio profesional. Así pues, el resto del capítulo está consagrado a la documentación digital para el traductor e intérprete de la TISP y en la actual relevancia de este aspecto para el desarrollo y la adquisición de la competencia léxica traductora en la TISP. Encontramos en concreto tres secciones en este capítulo, centradas en tres recursos digitales esenciales para la formación documental en la TISP y el posterior ejercicio profesional: fuentes lexicográficas electrónicas, corpus y programas de concordancias, y traducción automática junto a tareas de postedición. Para quienes queramos trabajar la documentación digital en clase, puede resultar de especial interés y actualidad la propuesta didáctica que la autora incluye al final de este último capítulo. En este caso, plantea utilizar la traducción ofrecida por distintos sistemas de traducción automática disponibles en internet y comparar los distintos errores que presentan siguiendo una lista adaptada por la propia autora basándose en el modelo de evaluación de calidad Multidimensional Quality Metrics de 2015. Tras ello, Sánchez Ramos propone 
finalizar el ejercicio con una tarea de postedición, campo que cada vez parece acercarse más a las aulas como reflejo de su creciente importancia en el mercado profesional actual.

En definitiva, esta obra se suma a los incansables esfuerzos para que la TISP siga abriéndose camino y consiga consolidarse en los estudios de Traducción. Se centra en dos aspectos primarios para este ámbito, como son el léxico y la documentación digital, los cuales se tratan desde un punto de vista tanto teórico como práctico. Todo ello hace que la monografía sea de gran valor y atractivo tanto para profesionales de esta disciplina como para formadores, investigadores o estudiantes. En particular, las aportaciones que la autora realiza a lo largo de la obra pueden resultar de un valor incuestionable para futuros estudios sobre el desarrollo del componente léxico de la TISP, o bien como base para un diseño curricular cuyo objetivo principal sea potenciar la competencia léxica de los traductores e intérpretes de esta disciplina.

Date of reception/Fecha de recepción: 12 de marzo de 2020

Date of acceptance/Fecha de aceptación: 14 de marzo de 2020

How to cite this article?/ ¿Cómo citar este artículo?

Pérez-Carrasco, Míriam (2020) “Reseña. María del Mar Sánchez Ramos. 2020. Documentación Digital y Léxico en la Traducción e Interpretación en los Servicios Públicos (TISP): Fundamentos Teóricos y Prácticos. Berlín: Peter Lang. 184 páginas. ISBN: 978-3-631-80849-8". FITISPosInternational Journal, 7 (1). 176-178. 